Radioprotection, vol. 44, $\mathrm{n}^{\circ} 5$ (2009) 1-4

(C) EDP Sciences, 2009

DOI: $10.1051 /$ radiopro/20095007

\title{
Radiological implications of NORM in the production of rare-earth compounds
}

\author{
P.P. Haridasan, P.M.B. Pillai, R.M. Tripathi and V.D. Puranik \\ Environmental Assessment Division, Bhabha Atomic Research Centre \\ Health Physics Unit, IREL, Udyogamandal, Kerala 683 501, India
}

\begin{abstract}
The composite rare earth chloride produced from monazite contain low levels of natural radionuclides and is being used as the input material for the production of individual rare earth compounds which have wide applications. Gross alpha, beta and ${ }^{228} \mathrm{Ra}$ activity concentrations in composite rare earth chloride and individual rare earth compounds such as oxides of $\mathrm{Ce}, \mathrm{Nd}, \mathrm{Pr}, \mathrm{Sm}, \mathrm{Gd}$ etc are presented. The significant radionuclide of environmental concern is identified as ${ }^{228} \mathrm{Ra}$ and the activity level varied between 0.1 and $7.8 \mathrm{~Bq} . \mathrm{g}^{-1}$ in different compounds. Sporadic ${ }^{228} \mathrm{Ra}$ levels up to $16 \mathrm{~Bq} . \mathrm{g}^{-1}$ was observed in Lanthanum oxide. The external gamma exposure rates and airborne activity due to thorium and thoron progeny in the process locations are studied. The activity levels in liquid effluent and potential exposure scenarios are indicated.
\end{abstract}

\section{INTRODUCTION}

Radiation protection and management of wastes generated by industries that process minerals and raw materials containing naturally occurring radioactive materials (NORM) are of concern in the context of long term environmental implications of waste disposal. Chemical compounds of rare-earth (RE) elements (La to Lu) have wide applications in daily life. They are commercially exploited from minerals such as monazite, bastnasite, xenotime, allanite etc. Most of these natural ores and minerals contain low or significant levels of thorium and uranium series nuclides. The thorium content varies from $0.1 \%$ to $10 \%$ and uranium content varies from very low percentage to $0.8 \%$ depending on the mineral and region of occurrence [1]. Monazite (Ce,La,Th) $\mathrm{PO}_{4}$, a phosphate mineral containing nearly $9 \%$ thorium as $\mathrm{ThO}_{2}$ is the starting material for the production of rare earth compounds in India. Caustic digestion followed by selective extraction in $\mathrm{HCl}$ is the method used to separate composite rare-earths chloride.

Limited studies on the radiation protection aspects in rare-earths industry are reported [2, 3]. A variety of diversified RE compounds that have wide applications in daily life and advanced scientific research are produced from the composite RE chloride by different chemical processes such as precipitation, solvent extraction and ion-exchange methods. The present studies are carried out in a rare-earths producing plant typically convert composite RE chloride to different compounds such as RE fluoride, oxide, carbonate and other individual rare earths compounds with emphasis on radiological aspects.

\section{MATERIALS AND METHODS}

Different types of rare earths compounds were collected from the production plant and analysed for gross alpha, gross beta and ${ }^{228} \mathrm{Ra}$ activity concentrations. The gross alpha and beta activity concentration in the samples were estimated by standard counting methods using a $\mathrm{ZnS}(\mathrm{Ag}$ ) alpha counter (Nucleonix Model.AP165) and a Geiger Muller counter (Nucleonix Model: RC605A). ${ }^{228}$ Ra activity in the samples were estimated by counting in a well-type $2^{\prime \prime} \times 2^{\prime \prime} \mathrm{NaI}(\mathrm{Tl})$ gamma spectrometer. (ECIL, Model SC604C). The combined ${ }^{228} \mathrm{Ac}$ peaks of $911 \mathrm{keV}$ and $960 \mathrm{keV}$ was used for the estimation of ${ }^{228} \mathrm{Ra}$ activity assuming transient equilibrium between the isotopes in the samples. The set-up was calibrated 
Table 1. Activity concentration in rare earth compounds.

\begin{tabular}{llll}
\hline Rare earth (RE) compounds & $\begin{array}{l}\text { Gross alpha } \\
\text { Bq.g }\end{array}$ & $\begin{array}{l}\text { Gross beta } \\
\mathrm{Bq}^{-1} \pm \mathrm{SD}\end{array}$ & $\begin{array}{l}{ }^{228} \mathrm{Ra} \\
\mathrm{Ra}\end{array}$ \\
\hline Composite RE chloride* & $1.3 \pm 0.6$ & $1.5 \pm 0.7$ & $0.45 \pm 0.20$ \\
RE fluoride & $4.3 \pm 0.8$ & $3.4 \pm 0.9$ & $1.23 \pm 0.27$ \\
RE carbonate & $7.0 \pm 1.0$ & $6.4 \pm 0.9$ & $3.80 \pm 0.45$ \\
RE oxide & $4.7 \pm 0.8$ & $4.2 \pm 0.8$ & $1.90 \pm 0.35$ \\
Cerium oxide - A grade & $14.5 \pm 1.2$ & $18.3 \pm 1.3$ & $5.20 \pm 0.70$ \\
Cerium oxide - B grade & $7.7 \pm 1.0$ & $10.3 \pm 1.1$ & $2.30 \pm 0.37$ \\
Cerium hydrate & $3.7 \pm 0.8$ & $3.5 \pm 0.9$ & $1.40 \pm 0.27$ \\
Cerium nitrate & $<0.5$ & $<0.5$ & $<0.15$ \\
Neodymium oxide & $3.1 \pm 0.7$ & $1.2 \pm 0.7$ & $0.20 \pm 0.12$ \\
Lanthanum oxide & $18.1 \pm 1.4$ & $22.4 \pm 1.4$ & $7.80 \pm 0.80$ \\
Praseodymium oxide(99\%) & $<0.5$ & $1.5 \pm 0.8$ & $0.54 \pm 0.20$ \\
Samarium oxide(99\%) & $1.3 \pm 0.6$ & $5.2 \pm 0.8$ & $0.83 \pm 0.27$ \\
Gadolinium oxide(99\%) & $<0.5$ & $1.7 \pm 0.8$ & $0.48 \pm 0.20$ \\
\hline
\end{tabular}

*Mean value of 15 samples. All other values are mean values of 3 samples each.

using a standard monazite ore of known ${ }^{228} \mathrm{Ra}$ content in an identical geometry. The typical counting time was $10000 \mathrm{~s}$ and the minimum detectable activity was $0.15 \mathrm{~Bq} \cdot \mathrm{g}^{-1}$ at $1 \sigma$ confidence level. The external gamma exposure rates at different locations were measured using a Scintillometer. Air samples were collected using vacuum pumps having a flow rate of $50 \mathrm{lpm}$. The samples were collected on glass fibre filter papers having a collection surface of $2.5 \mathrm{~cm}$ dia representing breathing zones. A programmed alpha counting method [3] was used to estimate potential alpha energy concentration (PAEC) due to thoron progeny and long-lived alpha activity. The committed annual effective dose from the inhaled intake of thorium activity was estimated. In the case of thoron progeny, the inhalation dose was estimated by using the dose conversion factor $1.67 \mathrm{mSv}$ per Working Level Month (WLM) as given by Basis Safety Standards [4]. In order to assess the radiological impact due to waste streams, samples of liquid effluent were collected from the plant analysed for gross alpha, gross beta and ${ }^{228} \mathrm{Ra}$ activities by the standard analytical procedures [5].

\section{RESULTS AND CONCLUSIONS}

Table 1 shows the gross alpha and beta activities and concentration of ${ }^{228} \mathrm{Ra}$ in different types of chemical compounds of rare earth produced. Wide variations in the activity levels were observed depending upon the process conditions and chemical nature of the compounds.

The composite rare earth chloride showed mean gross alpha activity of $1.3 \pm 0.6 \mathrm{~Bq} . \mathrm{g}^{-1}$ and beta activity of $1.5 \pm 0.7 \mathrm{~Bq} \cdot \mathrm{g}^{-1}$. As ${ }^{228} \mathrm{Ra}$ is expected to be the major contaminant in rare earth compounds extracted from monazite, analyses were carried out to assess ${ }^{228} \mathrm{Ra}$ activity in all the samples. The mean ${ }^{228} \mathrm{Ra}$ in rare earth chloride was found to be $0.45 \pm 0.2 \mathrm{~Bq} \cdot \mathrm{g}^{-1}$. The gross alpha and beta activities in other commercial grade rare earth samples such as oxides, carbonates, fluorides etc were in the range 2.2 to $18.1 \mathrm{~Bq} . \mathrm{g}^{-1}$ and 2.4 to $22 \mathrm{~Bq} . \mathrm{g}^{-1}$ respectively. ${ }^{228} \mathrm{Ra}$ in these samples varied between 0.87 and $7.8 \mathrm{~Bq} . \mathrm{g}^{-1}$. Higher activity was observed in lanthanum and cerium oxides. In lanthanum oxide, ${ }^{228} \mathrm{Ra}$ activity upto 16 Bq.g-1 was observed. High purity rare earth compounds showed still lower activity levels as expected. The ${ }^{228} \mathrm{Ra}$ activity levels were below the exemption limit as per the safety standards where a limit of $10 \mathrm{~Bq} \cdot \mathrm{g}^{-1}$ is specified for regulation [4].

\subsection{External gamma dose}

The external gamma exposure rates measured at different locations in the rare earth process pant are shown in Table 2 . The radiation fields were generally below $1 \mu \mathrm{Gy} \cdot \mathrm{h}^{-1}$. Accumulated sludge/scales in 
Table 2. External gamma exposure rates in rare earth compounds processing.

\begin{tabular}{|l|l|l|}
\hline \multirow{2}{*}{ Location } & \multicolumn{2}{l|}{ Gamma exposure rate $\left(\mu \mathrm{Gy} \cdot \mathrm{h}^{-1}\right)$} \\
\cline { 2 - 3 } & Range & Mean \\
\hline RE chloride storage tanks & $0.6-1.2$ & 1.0 \\
RE chloride storage tank - sludge/scales & $10-40$ & 15 (Max.100) \\
Cerium hydrate tanks & $0.3-0.7$ & 0.4 \\
RE carbonate tanks & $0.7-1.0$ & 0.8 \\
Mixer settlers - solvent extraction & $0.6-0.9$ & 0.8 \\
REF process tanks & $1.0-2.0$ & 2.0 \\
Calciner/Product drier & $0.5-1.0$ & 0.7 \\
Mixer settlers - cerium purification & $0.2-0.4$ & 0.3 \\
Filter presses & $0.4-0.6$ & 0.5 \\
General background & $0.3-0.8$ & 0.5 \\
\hline
\end{tabular}

the RE chloride solution storage tank showed gamma exposure rate upto $100 \mu \mathrm{Gy} \cdot \mathrm{h}^{-1}$. The average general background in the worker occupied areas was $0.5 \mu \mathrm{Gy} \cdot \mathrm{h}^{-1}$ and the natural background outside the plant premises was measured as $0.15 \mu \mathrm{Gy} \cdot \mathrm{h}^{-1}$. Hence the likely incremental external dose for the occupancy period of $2000 \mathrm{~h}$ in a year is estimated to be $0.7 \mathrm{mSv}$ and can be considered as the potential dose in the case of large scale processing of rare earth chloride to produce high purity RE compounds. As many of these compounds are used only in small quantities for various applications, the likely external dose received by a worker exposed to gamma from small quantities of the compounds is estimated to be in the range 0.03 to $1.3 \mathrm{mSv}$ per year using the conversion factors given by IAEA safety report series No.49 [6] for 2000 hours of occupation. In real situations the actual occupancy will be much lower and hence the likely external doses also will be much lower than estimated.

\subsection{Inhalation dose due to thoron progeny and long-lived alpha activity}

The potential alpha energy concentration (PAEC) due to thoron progeny and airborne long-lived alpha activity due to ${ }^{232} \mathrm{Th}$ in rare earth process plant are provided in Table 3. Measurements were carried out during the period 2003 to 2007.

The annual average PAECs were in the range $15-42 \mathrm{mWL}$ whereas individual samples showed PAEC ranging from 2 to $162 \mathrm{mWL}$. The average for the five years data is worked out to be $30 \mathrm{mWL}$. The derived air concentration limit for the occupational settings applicable to the plant is $1000 \mathrm{mWL}$ and the current levels are only $3 \%$ of the limit. Hence the annual inhalation dose to occupational workers due the intake of thoron progeny PAEC is estimated as $0.6 \mathrm{mSv}$, assuming $2000 \mathrm{~h}$ of work occupancy. Airborne ${ }^{232} \mathrm{Th}$ activity at various locations in the plant ranged between 0.001 and $0.023 \mathrm{~Bq} \mathrm{~m}^{-3}$. The mean activity during the period was $0.005 \pm 0.002 \mathrm{~Bq} \mathrm{~m}^{-3}$. Assuming a breathing rate of $1.2 \mathrm{~m}^{3} \mathrm{~h}^{-1}$ for 2000 working hours in a year, the likely inhalation dose is worked out as $0.62 \mathrm{mSv}$. Including the external dose component of $0.7 \mathrm{mSv}$, the likely total annual dose to occupational worker is estimated to be $1.92 \mathrm{mSv}$.

Table 3. Airborne activity in the RE Process plant.

\begin{tabular}{|c|c|c|c|c|}
\hline \multirow{2}{*}{ Year } & \multicolumn{2}{|c|}{ Thoron progeny, PAEC $(\mathrm{mWL})$} & \multicolumn{2}{c|}{${ }^{232} \mathrm{Th}\left(\mathrm{Bq} \cdot \mathrm{m}^{-3}\right)$} \\
\cline { 2 - 5 } & Range & Mean \pm SD & Range & Mean \pm SD \\
\hline 2003 & $5-90$ & $15 \pm 5$ & $0.001-0.012$ & $0.008 \pm 0.003$ \\
2004 & $7-155$ & $30 \pm 7$ & $0.002-0.014$ & $0.006 \pm 0.002$ \\
2005 & $5-148$ & $42 \pm 10$ & $0.001-0.023$ & $0.007 \pm 0.003$ \\
2006 & $3-162$ & $35 \pm 8$ & $0.001-0.018$ & $0.005 \pm 0.002$ \\
2007 & $2-139$ & $41 \pm 10$ & $0.001-0.011$ & $0.003 \pm 0.001$ \\
\hline
\end{tabular}


Table 4. Activity in liquid effluent before treatment.

\begin{tabular}{|l|c|c|}
\hline Activity & Range Bq..$^{-1}$ & Mean \pm SD, Bq..$^{-1}$ \\
\hline Gross alpha & $40-160$ & $107 \pm 62$ \\
Gross beta & $50-350$ & $142 \pm 69$ \\
${ }^{228} \mathrm{Ra}$ & $5-46$ & $24 \pm 10$ \\
\hline
\end{tabular}

\subsection{Effluents/wastes}

Table 4 gives the radioactivity analysis of the liquid effluent generated in the plant before treatment for final disposal into aquatic environs. The gross alpha, beta and ${ }^{228} \mathrm{Ra}$ activities in the effluent showed mean values $107 \pm 62,142 \pm 69$ and $24 \pm 10 \mathrm{~Bq} \cdot \mathrm{l}^{-1}$ respectively. These are treated to contain the activity levels specified by the regulators before discharge into the environment. The gaseous releases from the plant normally contain only low levels of thoron progeny. Measurements indicated no significant environmental concentration of thoron progeny attributable to the plant operation. As ${ }^{228} \mathrm{Ra}$ is observed to be the potential environmental contaminant further work on the ingestion dose contribution to the public through the waste disposal is required.

\section{Acknowledgments}

The authors are grateful to Mr. H.S. Kushwaha, Director, HS\&EG, Bhabha Atomic Research Centre, Mumbai for the guidance and support. The authors record their thanks to the management of M/s Indian Rare Earths Ltd. for facilities to carry out the work.

\section{References}

[1] Pillai, P.M.B., Naturally occurring radioactive materials (NORM) in the extraction and processing of rare earths. Proc. of Internat. Symp. On Norm, Sevilla, Spain, March 19-22, (2007). IAEA TECDOC.

[2] Lauria, D.C., Elanine.R.R.Rochedo., The legacy of monazite processing in Brazil, Radiat. Prot. Dosimetry, (2005) doi.10.1093/rpd/nci303.

[3] Haridasan, P.P., Studies on occupational inhalation exposures due to Thorium and its progeny in monazite mineral industry. Ph. D.Thesis, University of Mumbai (2002).

[4] International Atomic Energy Agency, Basic Safety Standards. Safety Series No.115 (Vienna: IAEA, 1996).

[5] Bhat, I.S., A.G. Hegde, M.A.R. Iyengar, N.N. Dey., Analytical Procedure Manual. BARC/ 1992/HPD/002.(1992).

[6] International Atomic Energy Agency, Safety Report No.49. Assessing the need for radiation protection measures in work involving minerals and raw materials Vienna, IAEA(2006). 